\title{
Understanding Etiology of Chromosome 21 Nondisjunction from Gene X Environment Models
}

\author{
Pinku Halder \\ University of Calcutta \\ Upamanyu Pal \\ University of Calcutta \\ Agnish Ganguly \\ University of Calcutta \\ Papiya Ghosh \\ Bijoy Krishna Girls' College (Affiliated to University of Calcutta) \\ Anirban Ray \\ Bangabasi Morning College (Affiliated to University of Calcutta) \\ Sumantra Sarkar \\ Diamond Harbour Government Medical College \& Hospital \\ Sujay Ghosh ( $\sim$ sgzoo@caluniv.ac.in ) \\ University of Calcutta
}

\section{Research Article}

Keywords: Down syndrome, nondisjunction, folate regulators, smokeless chewing tobacco, gene x environment.

Posted Date: August 4th, 2021

DOI: https://doi.org/10.21203/rs.3.rs-754161/v1

License: @ (i) This work is licensed under a Creative Commons Attribution 4.0 International License. Read Full License 


\section{Abstract}

Maternal risk factors and their interactions with each other that associate chromosome 21 nondisjunction are intriguing and need incisive study to be resolved. We determined recombination profile of nondisjoined chromosome 21 and maternal genotypes for four selected polymorphic variants from the folate regulators genes stratifying the women according to the origin of segregation error and age at conception. We conducted association study for genotype and maternal habit of smoke less chewing tobacco with the incidence of Down syndrome birth. Additionally, we designed various logistic regression models to explore the effects of genotype, smokeless chewing tobacco habit, maternal age at conception and all possible interactions among them on chromosome 21 nondisjunction. We found folate regulator gene mutations are associated with maternal meiosis II error. Regression models revealed smokeless chewing tobacco and folate regulator mutant genotypes interact with each other to increase the risk of reduced and peri-centromeric recombination events on chromosome 21 that nondisjoined at meiosis II in the oocytes and the effect is maternal age independent. We inferred maternal polymorphic genotypes and habit of smokeless chewing tobacco interact with each other and increase the risk of meiosis II error in oocytes in maternal age-independent manner.

\section{Introduction}

Down Syndrome (DS) or Trisomy 21 is the most frequent genetic form of intellectual disability in human and is caused by the failure of chromosomes to separate properly during meiosis, the error known as chromosome nondisjunction (NDJ). Among overwhelming majority of cases NDJ occurs at meiosis $\mathrm{I}^{1}$ of oogenesis ${ }^{2}$.

Maternal risk for DS child birth is multifactorial and includes factors of both genetic and environmental origin 1,3 and challenges faithful chromosome segregation either maternal age-dependent manner or a stochastic age-unrelated fashion ${ }^{4,5}$.Advanced maternal age ${ }^{6}$ and altered recombination profile of chromosome 21 (Ch21) are two risk factors that have been identified to be associated with DS birth risk in previous studies ${ }^{7}$. Reduction in recombination frequency of pairing Ch21 homologues and altered chiasma positions are two wellrecognized 'molecular' correlates of improper chromosome segregation ${ }^{8}$.In addition, some prospective candidates for epidemiological risk factors have been reported to be associated with DS birth ${ }^{9-11}$, though results are contradictory. Among them, maternal periconceptional drinking and smoking are common habits of women in western countries. Among Indian women use of Smokeless Chewing Tobacco (SCT) is highly prevalent. Studies conducted on human and mice reported genotoxic effects of smoking and tobacco use on reproductive health and fertility ${ }^{9,10,12}$.Previously, we analysed the association of SCT as the epidemiological risk factor of DS birth ${ }^{13}$ and found SCT was a significant risk factor for reduction in recombination frequency on Ch21q in maternal age-dependent manner. When tested for spatial distribution of single recombinant events on $21 \mathrm{q}$, we did not find any difference the SCT users from non-SCT users. Nevertheless, it is still obscure whether SCT interacts with any other risk factors when co-occur together or impose any synergistic effects in association with any other maternal genetic factors to imperil ideal chromosome segregation process. This issue could only be resolved by analysing 'gene X environment ( $\mathrm{X}$ X E) models' considering maternal genotype as genetic risk component on one hand and SCT use as environmental or epidemiological risk factor on the other hand. The G XE model is increasingly being explored in many studies on intellectual disabilities ${ }^{14,15}$.A substantial amount of human and animal data has proved that environmental or epidemiological influence can exacerbate the symptoms of many neurological disorders having susceptible genetic

background ${ }^{16,17}$.Keeping this fact in mind we were curious to look into whether maternal exposure to SCT interacts with maternal genetic risk factors like polymorphic variants of any gene that has been reported previously as risk for Ch21 NDJ to cause chromosome segregation error. Several polymorphic variants of many maternal genes exhibited specific association with either MI or MII segregation pattern as revealed from recent GWAS on the population from USA ${ }^{18}$.

Polymorphisms of maternal folate metabolic regulators have been identified as risk factors associated with DS birth ${ }^{19}$. It is hypothesized that deficiency in folate pathway may perturb the centromeric methylation pattern which is needed for its attachment with spindle and chromatid separation ${ }^{20}$. Methylenetetrahydrofolate reductase (MTHFR), Methionine Synthase Reductase (MTRR), Methionine Synthase (MTR) genes are key regulators of folate metabolism pathways and polymorphic variants of these genes have been reported as maternal risk factors for DS birth in many ethnic populations, though results are contradictory ${ }^{21-23}$. In our previous study ${ }^{24}$ we have reported association between maternal folate metabolic regulator polymorphisms and increase risk of MII NDJ of Ch21 in oocyte among the Bengali speaking women from West Bengal, India. In the present study, we have designed 'GXE models' to test how the genetic and the environmental or epidemiological factors interact to predispose women to have meiotic NDJ error and subsequent DS birth considering maternal habit of SCT use as environmental challenge and maternal genotypes of selected folate regulator 
variants as genetic risk factors. This study is important as it will reveal the complicated multidimensional interactions among the various risk factors that synergistically create a predisposing ambience of Ch21 NDJ in maternal ovary.

\section{Result}

\section{Epidemiological and clinical attributes of the study participants}

The estimated mean maternal age at conception of women in the Ml and MIl error groups having DS child were30.15 \pm 4.1 (mean \pm SD) \&30.02 \pm 3.4 (mean $\pm S D$ ) years, as compared with control group $29.91 \pm 3.9$ (mean $\pm S D$ ) years $(P=0.20$ for Ml vs Control, $P=0.65$ for MII vs Control) (Table 1). The mean age of control women with folate regulator wild genotypes was $33.09 \pm 3.1$ (mean \pm SD) years which is similar to the estimate $32.90 \pm 2.3$ (mean $\pm S D$ ) years for the MI women with $D S$ child $(P=0.13)$ and $33.10 \pm 3.3$ years for the MII womenwithDS child $(P=0.96)$. The mean age of control womenwith folate regulator mutant genotypeswas $31.91 \pm 3.5(m e a n \pm S D)$, which is again concordant with the estimated mean age 32.01 \pm 4.4 (mean $\pm S D$ ) years for MI mothers $(P=0.59)$ and $31.60 \pm 3.8$ (mean $\pm S D)$ years for MIl mothers $(P=0.18)$ havingDS child. When we compared the mean age of the women in Ml risk variant group with the MII risk variant group, the difference remained insignificant $(P=0.13)$. Moreover, the meiotic outcome groups did not exhibit significant difference in mean paternal age of conception when compared to control group ( $P=0.24 \mathrm{Ml}$ vs control; $P=0.72$ for $\mathrm{Mll}$ vs control). As we dealt with maternal errors and maternal genotypes only, we did not analyze paternal genotypes. The other epidemiological parameters remain concordant between $\mathrm{Ml}$ and $\mathrm{MII}$ case and control groups.

\section{Frequencies of SCT use in Control and Case groups by age categories}

A total of 1294 families with child having DS (Case) and 870 families with healthy child (Control) were included in this study. We categorized each of this group as 'SCT never-user' (case 0.64 vs control 0.83 ) and 'SCT ever-user' (case 0.36 vs control 0.17 ) subcategories according to the declared SCT use status in epidemiological record. We found significant difference in maternal SCT use with odds in favour of the case mothers $(\mathrm{OR}=2.772,95 \% \mathrm{Cl}=2.245-3.424, \mathrm{P}<0.0001)$ (Supplementary Table S1). We further stratified the case and the control women according to their age at conception as young ( $\leq 28$ years), middle (29 to 34 years) and old ( $\geq 35$ years)groups and tested if there was any significant difference in maternal SCT use pattern across the age. The frequency of SCT use between control and case group differ significantly in the young $(\mathrm{OR}=1.996,95 \% \mathrm{Cl}=1.468-2.634, \mathrm{P}<0.0001)$ and the middle age group $(\mathrm{OR}=1.458,95 \% \mathrm{Cl}=1.056-2.015, \mathrm{P}=0.024)$ but not in the older age group $(\mathrm{OR}=1.133,95 \% \mathrm{Cl}=0.760-1.686, \mathrm{P}=0.608)$ (Supplementary Table S2).

\section{Frequency of folate regulator polymorphism in case-control and meiotic outcome groups}

We calculated frequency of all tested polymorphic variants of folate metabolic regulators and considered the mothers who bear any of four tested polymorphisms together as a group and found $\sim 5$ folds increased odds in favour of case mothers over the controls $(\mathrm{OR}=5.338 ; \mathrm{Cl}=4.015-7.097 ; \mathrm{P}<0.0001)$. Out of the 1294 case mothers 956 and 338 were detected as $\mathrm{MI}$ and MII error categories, respectively. We have tested all four polymorphic variants, namely MTR A2756G, MTRR A66G, MTHFR C677T \& MTHFR A1298C for all $\mathrm{MI}$ and MII case samples. The frequency of polymorphic variants in meiotic outcome groups is given in Table 2. All four tested polymorphic variants exhibited strong association with maternal meiosis II NDJ error and this reconfirms the result that we obtained in

our previous study ${ }^{24}$. However, frequencies of all four polymorphic variants were estimated negligible in the MI NDJ group and so we considered only the MII group as case for further analyses that involve association study (Supplementary Table S3) and logistic regression modelling.

Some of the participating women carried more than one tested folate polymorphic genotype and for them we estimated synergistic effect through gene-gene interactions models for all four tested variants. All the possible genotype combinations of any two given loci at a time were tested taking wild type genotype as reference (Supplementary Table S4).

Further, we have designed hypothetical models to evaluate the additive risk of maternal genotypes in combination with all the tested variants (Supplementary Table S5) and found gradual increase in risk of DS birth with increasing number of risk alleles in the tested loci. When all four loci carry risk alleles together either in homozygous or heterozygous state in the tested models, a $\sim 17$ folds increase odds in favour of Mll errors was evident $(P<0.0001)$. When three out of four loci carried respective minor allele together, we estimated $\sim 9$ folds increased odds in favour of MIl error $(P<0.0001)$.

\section{Interactions among Risk factors}


We stratified the participating case mothers into three age categories, based on maternal age at the time of conception following our previous definition 5 : young ( $\leq 28$ years), middle (29-34 years) and old ( $\geq 35$ years). For all the analyses, the maternal age of conception was considered as proxy for oocyte age as direct estimation of the later was beyond the scope of the present study. We used binary logistic regression and liner regression models to study a variety of questions regarding interaction among genetic risk factors i.e., amount of recombination, location of recombination, folate regulator gene mutations and epidemiological risk factor i.e., maternal SCT use and their association with maternal age at conception of DS foetus. Our analyses and statistical modelling are designed to address the following principal questions: 1) Does any significant difference exist in the association of smokeless chewing tobacco (SCT) between cases and controls, and does this depend on maternal age and maternal folate regulator mutation or polymorphisms? 2) Considering only cases, is there any difference in SCT use among MI and MII error groups, and does this depend on maternal and folate regulator mutation or polymorphism? 3) Considering MI and MII cases separately, is there any relation between SCT use and the amount of meiotic recombination and does this depend on maternal age and does folate regulator mutation or polymorphisms have any effect on if? 4) Again, considering MI and MII cases separately, is there any relation between SCT use and the location of meiotic recombination and does this depend on maternal age and folate regulator polymorphisms? All these models explored the risk factors separately as well as considered them together to find any interaction among them that predispose women for having DS pregnancy.

\section{Model I: Effects of SCT and Genotype in Cases vs. Controls}

In case-control analyses we considered maternal age, maternal genotype and SCT use as predictors variables and DS birth as outcome. The frequencies of occurrence of errors in case and control groups stratified by maternal folate regulator polymorphic genotypes, maternal age at conception and SCT use status is represented in the Table 3.We found maternal age, folate polymorphic genotype and SCT as significant predictors $(P=0.00)$ with young with had more frequent meiotic errors and old group had the least frequent errors (Table 3). In logistic regression analyses we tested various models (Table 3 ) of interactions among the predictors. We found significant elevated odds in favour of case women in the interaction models, namely young age X SCT ever user X folate polymorphic genotype, middle age X SCT ever user X folate polymorphic genotype and old age X SCT ever user X folate polymorphic genotype. This suggests both the epidemiological and genetic risk factors together increase risk of NDJ error in all the age group. We obtained intriguing result in the model Old $\times$ SCT never-use $\times$ folate polymorphic genotype which increases odds nearly 6 folds $(P=0.00)$ in favor of case women.

\section{Model II: Effects of SCT and Genotypes in MI vs. MII}

This is case only analyses and we considered maternal age, maternal genotypes and maternal SCT use as predictors and meiotic errors as outcome variables. We observed more frequent incidence of DS birth among women with polymorphic genotype and SCT use in both the $\mathrm{Ml}$ and MII groups (Table 4) in compare to any other combinations of risk factors. Moreover, the DS birth incidence was more frequent among the younger mothers and gradually decreases with age. For example, we recorded frequency of MII error among the women who were SCT user and had polymorphic genotypes as $0.42,0.32$ and 0.26 (Table 4) for young, middle and older groups, respectively. Logistic regression models revealed interaction between SCT use and folate polymorphic genotypes as significant predictors of MII error(Table 4).Again, the interaction proved significant for all the age groups ( $\mathrm{OR}=21.48$ for young and middle age, $\mathrm{OR}=$ 24.1 for old age group; $P=0.00$ for all the model). Interestingly, we found significant odds in favour of MIl error for the interaction term SCT never use $X$ folate polymorphic genotypes in all the age groups which suggest the maternal folate polymorphic genotypes impose risk of MII NDJ even in absence of SCT.

\section{Model III: Effects of SCT and Genotype on amount of recombination in M-II NDJ group}

Table 5 represents the frequency of single observed recombination events among MII women stratified by their SCT use status, folate polymorphic genotypes and age at conception. We observed reduction in double crossover frequency among the polymorphic genotype bearing and SCT user women than any other categories. We scored frequency of double recombinants among young, middle and older women as $0.13,0.36$ and 0.44 , respectively for the SCT user mutant genotype women in contrast to $0.48,0.56$ and 0.68 in the respective age categories of wild type SCT never user group. Pair wise comparison among the tested categories was conducted using chi square tests. We found significant difference between 'young wild type SCT never-user' and 'young wild type SCT ever-user' ( $P=0.01)$, 'young wild type SCT never-user and young folate polymorphic genotype SCT never-user' ( $P=0.01)$,' young wild type SCT never-user and young folate polymorphic genotype SCT ever-user' $(P=0.0006)$ pairs. Interestingly, maximum difference in frequency of recombinant events was recorded $(P=0.006)$ for the pairs 'young wild type SCT never-user' and 'young folate polymorphic genotype SCT ever-user' with only $13 \%$ of all observed double recombination in the latter group. No other pair-wise comparisons were proved significant. Another important observation is that the differences were recorded within the young age category, not in other age groups and this suggests that the effects of risk genotypes and SCT use are maternal age independent. 
To find out true interactions among the risk factors we performed logistic regression analysis considering maternal age, maternal habits of SCT, maternal folate regulator genotypes as predictors and amount of recombination on nondisjoined Ch21 as outcome variables. In these analyses we used the interaction term 'young X SCT ever use $X$ wild genotype' as reference. Significant interactions were recorded only in the young age category with 'SCT ever use $X$ wild genotype' $(P=0.027)$, 'SCT ever use $X$ folate polymorphic genotype' $(P=0.002)$ and 'SCT never use $X$ folate polymorphic genotype' $(P=0.021)$. No other models for other age groups were proved significant (Supplementary Table S6).

\section{Model IV: Effects of SCT and Genotype on spatial distribution of the observed single recombination events in MII NDJ group}

Table 6 represents the distribution of single recombinant events along 21q of MIl errors group stratified by maternal genotype, SCT use status and age at conception. The single observed recombination events show a change in spatial distribution pattern from the middle of the chromosome arm in the young age group to the centromere proximal position in the older age group in 'wild type SCT never-user women' and this observation is consistent with the findings from the previous studies ${ }^{4,5}$. We observed more frequent single recombination events in the pericentromeric regions in the SCT ever-user group as well as among the folate polymorphic genotype bearing women. This is a new finding. We scored $~ 18 \%$ of all observed single recombination events in the centromere proximal intervals 1 and 2 among the 'young SCT never-user wild genotype' women in contrast to $~ 81 \%$ of all single recombination events in 'young-folate polymorphic genotype SCT ever user group' (Table 6). Interestingly, the distribution pattern of single observed recombination events across the age groups remained similar among the women who were SCT ever-user as well as had folate polymorphic genotypes. In other words, we did not observe any displacement of single recombinant events towards centromere with age among SCT user folate polymorphic genotype women. This observation is also novel. We compared the spatial distribution of single observed recombinant events among the age groups in pairwise manner through chi square and found significant difference in the younger age group between 'wild type-SCT never-users' vs 'folate polymorphic-SCT ever-user' ( $P<0.0001)$, 'wild type-SCT ever user' vs 'folate polymorphic-SCT ever-users' ( $\mathrm{P}<0.0001)$ and 'folate polymorphic-SCT never-users' vs 'folate polymorphic-SCT ever-users' (P $<0.0001)$. Careful observation revealed both 'SCT use' and 'folate polymorphic genotype' has an effect on recombination displacement towards centromere (Table 6).

In evaluating the effect of interactions among the predictors on the placement of single recombinant events on the 21q we did linear regression analyses considering younger age group as reference. Unlike logistic regression we considered any two predictors at a time in a given interaction model(Supplementary Table S7).We did this owing to inability of converting the position of single recombinant events into binary variables needed for data entry in logistic regression program. When considered individually, only maternal age at conception revealed as significant predictors of position of single recombinant events. Significant effects were recorded for the models 'old age X SCT ever-user' ( $P=0.00)$, 'old age $x$ folate mutant genotype' $(P=0.00)$ and 'SCT ever-user $X$ folate mutant genotypes' $(P=0.005)$. This observation suggests any two risk factors when present together influence effectively the position of recombination events and probably caused more centromere proximal recombinant events on $21 \mathrm{q}$.

\section{Discussion}

Complex genetic disorders usually have underpinning genetic and environmental components as causative factors. The 'G X E model' of human disease manifestation considers genetic makeup as 'loaded gun' on which 'environmental trigger' works. The story of chromosome NDJ is not as simple as it was thought initially. Studies have characterised the maternal age, maternal recombination anomalies on one hand and epidemiological or environmental factors on the other hand as the risk factors for NDJ. Incisive analyses have revealed complex multifactorial nature of etiology of Ch21 NDJ and the exploration of ' $G$ X E model' became obvious to get a holistic view of the risk paradigm of DS birth. We for the first time ever tried to figure out the 'GXE models' to resolve intriguing etiology of human aneuploidy taking advantage of the largest sample cohort with DS used ever in epidemiology study and unique records regarding SCT use by Indian women. We considered all the risk factors that we analysed in our previous studies ${ }^{5,11,13,24}$ and these are maternal age, maternal use of SCT, maternal folate metabolic regulator genotypes.

We have tested the association of SCT use and specific folate regulator polymorphisms with the case-control and MI-MII categories stratified by maternal age at conception. The case control study demonstrated strong association of SCT use with NDJ errors among the DS bearing women with stronger effect in the young age group $(P<0.0001)$, than the middle age women $(P=0.02)$ and no association in old age women (Supplementary Table S2). This observation supports the notion that SCT challenges faithful chromosome segregation irrespective of age at conception of the women. 
We analysed maternal genotypes of selective variants of the folate regulator genes, namely MTR A2756G, MTRR A66G, and MTHFR C677T \& MTHFR A1298C. These variants were reported to be associated with DS birth in different ethnic populations ${ }^{25-27}$. We tested association of all four variants and obtained significant elevated odds in favour of the Mll error group over the Ml error group for homozygous minor and heterozygous genotypes of all four polymorphic sites except the GG of MTR A2756G (Table 2).

We designed several ' $G$ XE models' and conducted logistic regression analyses considering maternal age, maternal folate regulator genotypes, maternal habits of SCT use and interaction terms among them as predictors for different outcome variables like incidence of DS birth, types of meiotic errors, recombination amount and position of single recombinant events on $21 \mathrm{q}$. In case-control analyses we obtained significant effects for the interaction terms 'young age X SCT ever user X folate mutant', 'middle age X SCT ever user X folate mutant' and 'old age X SCT ever user X folate mutant'(Table 3) on the incidence of DS birth. Moreover, we observed a gradual reduction in the frequency of DS birth incidence with age ( 0.42 young, 0.32 middle and 0.26 old MII) among the women who are folate polymorphic genotype carriers as well as SCT user and this trend supports the hypothesis that the interactions between SCT use and folate mutant increases risk of DS birth incidence in maternal age independent manner. The rationale of this inference is that any risk factor that is age dependent shows highest frequency in young age group which is not otherwise suffers from age related challenges. On contrary, age related risk factors show increasing frequency with age.

In the second model which is a case only study we analysed the effects of all the risk factors and their interaction terms on the types of meiotic error, i.e., $\mathrm{MI}$ and $\mathrm{MII}$. As the biology of $\mathrm{Ml}$ and $\mathrm{MII}$ is different we performed this analysis to get insight into the imperilment incurred by risk factors on the specific mechanism of meiotic chromosome segregation. We observed highest frequency of the folate metabolic regulator variants among the younger women within the MII group with gradual decrease in frequency with age (Table 4). This observation confirms our previous ${ }^{24}$ hypothesis that folate metabolic regulator polymorphisms are the risk factors for MII errors, probably affect chromatid separation at advanced phase of oogenesis and the effects is probably maternal age independent following the rationale explained above. In regression analyses for various interactions among the predictors we observed many folds elevated odds in favour of MII errors for the interaction terms 'young age X SCT ever-user X folate polymorphic genotypes', 'Middle age X SCT ever-user X folate polymorphic genotype' and 'old age X SCT ever-user X folate polymorphic genotypes' (Table 4). This observation suggests combined effect of maternal risk genotype and maternal exposure to SCT elevates risk of MII NDJ in maternal age independent manner. Interestingly, we obtained significant interaction between 'folate genotype' and 'SCT never use' group for all the age categories, though the odds were less than the odds estimated for the interaction term 'SCT use X folate polymorphic genotype'. This observation in turn suggests that the folate polymorphic variants are significant risk factors for Mll errors for all age groups and the risk is exacerbated in association with maternal SCT use. This hypothesis needs further evidence in favour to be confirmed.

In analysing effects of SCT use and folate regulator mutant genotypes on the amount of recombination we observed gradual decrease infrequency of single recombinant event and gradual increase in frequency double recombinant events with advancing age of MII women when stratified with age at conception and SCT use status. This observation is novel. Significant difference in distribution of recombinant events was obtained by chi square test for the pairs within the young group namely, 'wild type SCT never-use' vs 'wild type SCT ever-use', 'wild type SCT never-user vs folate polymorphic genotype never-use' and 'wild type never-use' vs 'folate polymorphic genotype-SCT ever use'. Rest of the pair wise comparisons for the other age groups were insignificant (Table 5). These results suggest SCT use and polymorphic genotype probably reduce the frequency of recombinant events on $21 \mathrm{q}$ and the effect is maternal age independent. That is why significant difference is obtained only in young age group. This hypothesis is further supported by the results of logistic regression models considering above mentioned genetic, epidemiological factors and their interaction terms as predictors and amount of recombinant as outcome. We obtained significant effects in the models 'young age X SCT never-user $X$ folate polymorphic genotype', 'young age X SCT ever-user X folate polymorphic genotype' (Supplementary Table S6) with strongest effect for the later (P = 0.002). This result intuitively suggests both the 'folate polymorphic genotypes' and 'SCT-use' reduce the recombinant event on $21 \mathrm{q}$ among the young women independently and their interaction has stronger effects which imperil sister chromatid separation at MII. Further, it can be inferred that SCT-use and polymorphic genotypes affect young age more than older age.

Lastly, we analysed the effects of 'SCT use' and 'folate polymorphic genotype' on the spatial distribution of single recombinant events on 21q of MIl events. Previously we and others have observed ${ }^{4,5}$ that peri-centromeric single exchange is risk of MIl errors at older age. We observed almost similar distribution of single recombinant events in the pericentromeric interval 1 across the age groups in 'folate polymorphic genotypes-SCT use category' (Table 6). This is a novel observation. We obtained significant difference in chi square test in pair wise comparison only between 'wild type - SCT never-user' vs 'folate polymorphic variant - SCT user'. This suggests' SCT use' and 'folate polymorphic genotypes' have combined effects in displacement of recombinant events towards centromere of $21 \mathrm{q}$ in all age groups. The analyses of interactions among the predictors through regression models revealed significant effects of 'SCT-ever use X 
folate polymorphic variant genotypes', 'SCT X old age' and 'old age X 'folate polymorphic genotypes' interaction terms (Supplementary Table S7). This outcome suggests any two of the three risk factors i.e., 'SCT use', 'folate polymorphic genotypes' and 'old age' when present together increase risk of incorrectly positioned single recombinant events towards centromere which probably cause chromosome entanglement and non-separation of sister chromatids in MII. Though, this hypothesis is speculative and need further incisive study to be confirmed. It is very difficult to justify why distribution of single recombinant events in the interval 1 is almost similar across the age group in one hand, but significant interaction was obtained with the old age group only in the regression model on the other hand. It may be possible that age of women has stronger effects on the anomalous positing of single recombinant events on $21 \mathrm{q}$ than other age groups.

In summary, we for the first time ever demonstrated interactions between maternal 'SCT use' and 'maternal polymorphic genotype of folate regulator genes' that increase risk of reduced recombination and pericentromeric single recombinant events on the Ch21, which nondisjoined at MII. This effect is probably maternal age independent. Previously we ${ }^{13}$ observed maternal 'SCT use' was associated with the MII errors and reduced the recombination frequency. Therefore, the outcome of the present study confirms the notion that SCT in interaction with maternal folate polymorphic genotypes increases the chance of anomalous placement of recombination. This observation is novel as we did not find this association in any other published literatures. More incisive analyses are needed to resolve this issue.

Limitation of our present study is to overlook the other polymorphisms (besides the tested four) of the folate regulator genes in maternal genome which may have some confounding effects in the present outcome. But again, it is difficult at moment to differentiate the contribution of the tested four polymorphisms on observed incidence of meiotic errors from the share of the other genetic risk factors that we did not considered in the study. Moreover our study suffers from lack of supportive evidence from other studies. Nevertheless, our work is the pioneer attempt to address the critical issue of interaction between genetic and environmental risk factors in the intriguing etiology of Ch21 NDJ and birth of child with DS. This result will provide foundation to design 'G X E models' for other human aneuploidy and complex genetic disorders. These findings bring us a significant step closer towards understanding the cause Ch21NDJ in the human oocyte.

\section{Methods}

\section{Sample collections and epidemiological data recordings}

\section{Trisomic samples}

Families were referred to the laboratory from Kolkata and its surrounding Medical Colleges and Hospitals by the clinician collaborators. A total of 1294 families, each with single child with DS having free trisomy 21 were included in this study. Eligibility criteria for selecting Trisomic samples were availability of complete set of tissue samples from DS family trios, free trisomy 21 and live born child with DS as determined by classical karyotyping at our laboratory and complete information regarding maternal life style, especially periconceptional Smokeless Chewing Tobacco (SCT) use and related issues. Interviews of mothers were taken very privately, in person, after obtaining full consents. A pre-printed, extensive set of questions was used for each family to collect detailed family history, information about lifestyle, history of miscarriage or abnormal pregnancy outcome if any and other relevant epidemiological details. The confidentiality of all information was maintained very carefully at our laboratory. The participating cohort sample consisted chiefly of Bengali-speaking families from West Bengal; the majority believed in either Hinduisms or Islam.

\section{Controls}

A total of 870 families, each having healthy euploid $(2 n=46, X X$ or $46, X Y)$ infant were recruited as the controls and their karyotype was confirmed through classical karyotyping at our laboratory. The controls were identified and selected randomly from healthy new-borns without any birth defect from the enrolled patient databases and birth registers of the hospitals that provided the cases to ensure maximum similarity in demographic attributes between the participating cases and controls. The minimum eligibility criteria for enrolment of control family were the completion of the maternal questionnaire and availability of at least maternal and child tissue samples.

\section{Tissue collection}

Tissue samples were donated voluntarily by the families following their understanding of use of tissue in academic research and its importance as explained by the clinician or by the first author of this manuscript. Informed consent for tissue uses in research was 
obtained from each of the participating families. Tissue samples were collected from trisomic family trios (Cases) i.e., DS child, father and mother as well as from the families with euploid baby (Controls). Nearly $2 \mathrm{ml}$ of venous blood samples were collected by venipunctute method in EDTA coated vacutainer tubes and were stored in $-20^{\circ} \mathrm{C}$ refrigerator till DNA isolation was done. The highest biomedical ethics were maintained during the study.

\section{Genotyping and recombination scoring}

\section{DNA isolation}

Genomic DNA was isolated from all blood samples by using QIAamp Blood Mini Kit (QIAGEN, Hilden, Germany) according to the manufacturer's instructions.

\section{Detection of parental origin and stage of meiotic nondisjunction}

Each participating family was genotyped with a panel of Ch21q specific short tandem repeat (STR) markers, covering from the pericentromeric region to the telomere (Fig. 1). These markers were used for determining parental origin of error as well as meiotic stage of error of NDJ. The parental origin of NDJ was determined by detecting the contribution of parental alleles to the probands for multiple markers. We inferred a Ml error when the parental heterozygosity of the pericentromeric markers was retained in the trisomic child (i.e., the marker was "nonreduced") and MII error when parental heterozygosity was "reduced" to homozygosity. MIl events with no evidence of recombination were considered to be mitotic errors and were excluded, as described elsewhere ${ }^{4}$. Earlier study has reported that some proportion of so-called MII errors actually originate at meiosis I. Despite this fact, we took the conventional approach to define "Ml" and "MII" errors as we did in our previous studies ${ }^{5,13}$. The determination of MI or MII was done blinded without knowing status of the epidemiological risk exposure of the women and their genotypes of selected polymorphic loci of folate metabolic regulators.

\section{Characterization of observed recombinant events on $21 \mathrm{q}$}

Standard methods for trisomic data ${ }^{28}$ were used for scoring recombination events. This recombination scoring is possible even though only one child is genotyped, owing to the fact that trisomic child bears two copies of Ch21 and thus is essentially a self-contained sibling pair for that chromosome. We did not estimate recombination in the control subjects as conventional recombination scoring requires either grandparents or at least two siblings which were not available for all the subjects. Thus, recombination was considered only in the case-only phase of our analysis.

Apart from four pericentromeric markers mentioned earlier, all additional markers were used to divide entire chromosome $21 \mathrm{q}$ into six intervals to monitor the recombinant events. After genotyping we recorded the marker status as reduced $(R)$, nonreduced $(\mathrm{N})$ or uninformative $(\mathrm{U})$ and arranged them successively in linear direction from centromere to telomere of $21 \mathrm{q}$ arm. The recombination event was scored whenever we observed a transition of two successive markers from nonreduced $(N)$ to reduced $(R)$ or reduced $(R)$ to nonreduced $(\mathrm{N})$ in the ordered panel of makers along the $21 \mathrm{q}$.

\section{Detection of Folate metabolic regulator polymorphisms}

Bi-directional Sanger sequencing method was used to determine the maternal genotype for four polymorphic sites namely, MTR A2756G (rs1805087), MTRR A66G (rs1801394), MTHFR C677T (rs1801133) and MTHFR A1298C (rs1801131). All primers were designed by Primer3 (v.0.4.0) program and tested by OligoAnalyzer tool from Integrated DNA Technology (IDT). The PCR amplification was performed in a $30 \mu$ reaction volume containing 50-100 ng of DNA, $1 \mu \mathrm{l}$ of each primer ( $10 \mathrm{mmol} / \mathrm{L}), 0.2 \mu \mathrm{l}$ of deoxyribonucleotide triphosphate mix (dNTPs, $10 \mathrm{mmol} / \mathrm{L}$; Invitrogen Carlsbad, CA, USA), $1.5 \mu \mathrm{l}$ magnesium chloride $(\mathrm{MgCl} 2,50 \mathrm{mmol} / \mathrm{L}), 1 \times \mathrm{PCR}$ reaction buffer and $0.8 \mu$ of Taq Polymerase ( 5 units $/ 1 \mu \mathrm{l}$; Invitrogen, California, USA). Sanger sequencing was done using a Taq Dye Deoxy Terminator sequencing kit (Applied Biosystems, Foster City, USA) with an ABI Prism 377 DNA sequencer (Applied Biosystems, Foster City, USA). The primer sets used for Sanger sequencing are:

MTR A2756G (rs1805087): FORWARD -5' GTCTCCCAGAAACCAGTCAA 3'/ REVERSE 5' TCTAGCACAGCCCCTAACAC 3',

MTRR A66G (rs1801394): FORWARD - 5' TCGTACACTCTCCTTAATTTGATG 3'/ REVERSE -5' GATTCAAGAGGTGGAAAGCA 3', MTHFR C677T (rs1801133): FORWARD -5' ACAGTGTGGGAGTTTGGAG 3'/ REVERSE 5' AGTTCTGGACCTGAGAGGAG 3', MTHFR A1298C (rs1801131): FORWARD -5' CCTCCAGACCAAAGAGTTAC 3'/ REVERSE -5' CTGTGAGTTGATGGTGAGG 3', 
The reaction condition for sequencing PCR was: initial denaturation at $94{ }^{\circ} \mathrm{C}(5 \mathrm{~min})$, annealing at $55^{\circ} \mathrm{C}(30 \mathrm{~s})$, elongation at $72{ }^{\circ} \mathrm{C}(30$ s) and a final elongation at $72{ }^{\circ} \mathrm{C}(5 \mathrm{~min})$ for a total of 40 cycles.

\section{Statistical analysis}

All the analyses were done using software package STATA 13 (StataCorp LP, College Station, Texas). We have described the folate regulator gene mutations or polymorphisms as 'folate polymorphic genotype' for simplicity in rest of the manuscript. We considered twotailed $\mathrm{P}$ value $<0.05$ as significant alpha level for all statistical test.

\section{Declarations}

\section{Data availability}

All data generated or analysed during this study are included in this article (and its Supplementary Information files).

\section{Ethics declarations}

The experimental protocols and analyses were reviewed and approved by the ethics committee constituted by the University of Calcutta and IPGMER, Kolkata, India. The study was conducted following ethical compliance as outlined by declaration of Helsinki and Indian Council of Medical Research (ICMR).

\section{Consent statement}

Informed consents in the pre-printed questionnaire were taken from all participating families.

\section{Acknowledgements}

We are indebted to the participating families and physician friends who helped in procuring tissue samples.

\section{Author contributions}

SG conceptualized and conceived the study. SG, PG, and PH designed the study. PH, UP, AG, and SS collected samples and recorded epidemiological details. PH., UP, AG, and AR., performed data extraction. PH, AR, and SG analysed the results and provided interpretation. SG, and PG. wrote the manuscript. All authors read and approved the final version of the manuscript.

\section{Funding}

The work was funded by the grant from the Department of Science and Technology, Government of West Bengal (DST, WB)Grant no. SG/WBDST/S\&T 1000114/2016 and UGC-UPEII, DST-PURSE programs Grant no.UGC/859/UPE-2 BIO. Pinku Halder is thankful to University Grant Commission, New Delhi, India for the fellowship award.

\section{Competing interests}

The authors declare no competing interests.

\section{References}

1. Sherman, S. L., Allen, E. G., Bean, L. H. \& Freeman, S. B. Epidemiology of Down syndrome. Ment Retard Dev Disabil Res Rev13, 221227 (2007).

2. Freeman, S. B. et al. The National Down Syndrome Project: design and implementation. Public Health Rep.122, 62-72 (2007).

3. Ghosh, S., Bhaumik, P., Ghosh, P. \& Dey, S. K. Chromosome 21 non-disjunction and Down syndrome birth in an Indian cohort: analysis of incidence and aetiology from family linkage data. Genet. Res. (Camb.)92, 189-197 (2010).

4. Oliver, T. R. et al. New insights into human nondisjunction of chromosome 21 in oocytes. PLoS Genet.4, e1000033 (2008).

5. Ghosh, S., Feingold, E. \& Dey, S. K. Etiology of Down syndrome: Evidence for consistent association among altered meiotic recombination, nondisjunction, and maternal age across populations. Am. J. Med. Genet. A149A, 1415-1420 (2009). 
6. Hassold, T. \& Chiu, D. Maternal age-specific rates of numerical chromosome abnormalities with special reference to trisomy. Hum. Genet.70, 11-17 (1985).

7. Sherman, S. L. et al. Trisomy 21: association between reduced recombination and nondisjunction. Am. J. Hum. Genet.49, 608-620 (1991).

8. Hultén, M. A., Patel, S., Jonasson, J. \& Iwarsson, E. On the origin of the maternal age effect in trisomy 21 Down syndrome: the Oocyte Mosaicism Selection model. Reproduction139, 1-9 (2010).

9. Chen, C. L., Gilbert, T. J. \& Daling, J. R. Maternal smoking and Down syndrome: the confounding effect of maternal age. Am. J. Epidemiol.149, 442-446 (1999).

10. Kaufman, M. H. Ethanol-induced chromosomal abnormalities at conception. Nature302, 258-260 (1983).

11. Ray, A. et al. Maternal telomere length and risk of down syndrome: epidemiological impact of smokeless chewing tobacco and oral contraceptive on segregation of chromosome 21. Public Health Genomics19, 11-18 (2016).

12. Yang, Q. et al. Risk factors for trisomy 21: maternal cigarette smoking and oral contraceptive use in a population-based case-control study. Genet. Med.1, 80-88 (1999).

13. Ghosh, S. et al. Epidemiology of Down syndrome: new insight into the multidimensional interactions among genetic and environmental risk factors in the oocyte. Am. J. Epidemiol.174, 1009-1016 (2011).

14. Chokroborty-Hoque, A., Alberry, B. \& Singh, S. M. Exploring the complexity of intellectual disability in fetal alcohol spectrum disorders. Front. Pediatr.2, 90 (2014).

15. Kong, Y., Zhou, W. \& Sun, Z. Nuclear receptor corepressors in intellectual disability and autism. Mol. Psychiatry25, 2220-2236 (2020).

16. Pietropaolo, S., Crusio, W. E. \& Feldon, J. Gene-Environment Interactions in Neurodevelopmental Disorders. Neural Plast.2017, 9272804 (2017).

17. Chaste, P. \& Leboyer, M. Autism risk factors: genes, environment, and gene-environment interactions. Dialogues Clin Neurosci14, 281-292 (2012).

18. Chernus, J. M. et al. A candidate gene analysis and GWAS for genes associated with maternal nondisjunction of chromosome 21. PLoS Genet.15, e1008414 (2019).

19. Coppedè, F. The genetics of folate metabolism and maternal risk of birth of a child with Down syndrome and associated congenital heart defects. Front. Genet.6, 223 (2015).

20. Hernández-Saavedra, D., Strakovsky, R. S., Ostrosky-Wegman, P. \& Pan, Y.-X. Epigenetic regulation of centromere chromatin stability by dietary and environmental factors. Adv. Nutr.8, 889-904 (2017).

21. Grillo, L. B. das N., Acácio, G. L., Barini, R., Pinto, W. \& Bertuzzo, C. S. [Mutations in the methylene-tetrahydrofolate reductase gene and Down syndrome]. Cad Saude Publica18, 1795-1797 (2002).

22. da Silva, L. R. J. et al. Relationship between polymorphisms in genes involved in homocysteine metabolism and maternal risk for Down syndrome in Brazil. Am. J. Med. Genet. A135, 263-267 (2005).

23. Bosco, P. et al. Methionine synthase (MTR) 2756 (A $\rightarrow$ G) polymorphism, double heterozygosity methionine synthase 2756 AG/methionine synthase reductase (MTRR) 66 AG, and elevated homocysteinemia are three risk factors for having a child with Down syndrome. Am. J. Med. Genet. A121A, 219-224 (2003).

24. Halder, P. et al. Polymorphisms of folate metabolism regulators increase risk of meiosis II nondisjunction of chromosome 21 in oocyte. Meta Gene22, 100606 (2019).

25. Fong, C.-S. et al. Association of MTHFR, MTR, and MTRR polymorphisms with Parkinson's disease among ethnic Chinese in Taiwan. Clin. Chim. Acta412, 332-338 (2011).

26. Coppedè, F. et al. The MTRR $66 \mathrm{~A}>\mathrm{G}$ polymorphism and maternal risk of birth of a child with Down syndrome in Caucasian women: a case-control study and a meta-analysis. Mol. Biol. Rep.41, 5571-5583 (2014).

27. Moustafa, M., Gaber, E. \& El Fath, G. A. Methionine synthase A2756G and reduced folate carrier1 A80G gene polymorphisms as maternal risk factors for Down syndrome in Egypt. Egyptian Journal of Medical Human Genetics17, 217-221 (2016).

28. Feingold, E., Brown, A. S. \& Sherman, S. L. Multipoint estimation of genetic maps for human trisomies with one parent or other partial data. Am. J. Hum. Genet.66, 958-968 (2000).

\section{Tables}

Page 10/19 
Table 1. Demographic and epidemiological detail of participating families in the study. DS refer to Down syndrome; MI refer to Meiosis I; MII refer to Meiosis II and SD: Standard Deviation.

\begin{tabular}{|c|c|c|c|c|}
\hline \multirow{2}{*}{\multicolumn{2}{|c|}{ Criteria }} & \multicolumn{2}{|c|}{ DS bearing women } & \multirow{2}{*}{$\begin{array}{l}\text { Control } \\
\text { women }\end{array}$} \\
\hline & & MI & MII & \\
\hline \multicolumn{2}{|c|}{ Families participated in the study } & 956 & 338 & 870 \\
\hline \multicolumn{2}{|c|}{ Mean maternal age at conception (all referred cases) [YeartSD] } & $\begin{array}{l}30.15 \pm \\
4.10\end{array}$ & $30.02 \pm 3.40$ & $29.91 \pm 3.90$ \\
\hline \multicolumn{2}{|c|}{ Mean maternal age of women with Folate regulator wild genotypes [Year \pm SD] } & $\begin{array}{l}32.90 \pm \\
2.30\end{array}$ & $33.10 \pm 3.30$ & $33.09 \pm 3.10$ \\
\hline \multicolumn{2}{|c|}{ Mean maternal age of women with Folate regulator mutant genotypes [Year \pm SD] } & $32.01 \pm 4.40$ & $31.60 \pm 3.80$ & $31.91 \pm 3.50$ \\
\hline \multicolumn{2}{|c|}{ Mean paternal age at conception. (all referred cases) [Year士SD] } & $32.80 \pm 4.10$ & $32.90 \pm 7.20$ & $33.01 \pm 3.40$ \\
\hline \multicolumn{2}{|c|}{ Preconceptionmaternal folic acid intake amount (mean \pm SD $\mu \mathrm{m} /$ day) } & $432.5 \pm 6.1$ & $355.7 \pm 7.2$ & $536.5 \pm 2.5$ \\
\hline \multirow{3}{*}{$\begin{array}{l}\text { Socio-economic condition of } \\
\text { families }\end{array}$} & Low(<INR30,000/Month)[Frequency] & $295[0.31]$ & $186[0.55]$ & $323[0.37]$ \\
\hline & $\begin{array}{l}\text { Middle (INR 30,000-50,000/month) } \\
\text { [Frequency] }\end{array}$ & $517[0.54]$ & $118[0.35]$ & $443[0.51]$ \\
\hline & High (INR >50,000/month) [Frequency] & $144[0.15]$ & $34[0.1]$ & $104[0.12]$ \\
\hline \multirow{3}{*}{ Locality } & Kolkata metropolitan [Frequency] & $698[0.73]$ & $213[0.63]$ & $609[0.70]$ \\
\hline & Suburbs [Frequency] & $172[0.18]$ & $71[0.21]$ & $174[0.20]$ \\
\hline & Rural [Frequency] & $86[0.09]$ & $54[0.16]$ & 87[0.10] \\
\hline \multirow{3}{*}{ Religion } & Hindu[Frequency] & $851[0.89]$ & $247[0.73]$ & $792[0.91]$ \\
\hline & Islam [Frequency] & $86[0.09]$ & $71[0.21]$ & $52[0.06]$ \\
\hline & Others [Frequency] & $19[0.02]$ & $20[0.06]$ & $26[0.03]$ \\
\hline \multirow[t]{2}{*}{ Genotype status } & Wild type genotype[Frequency] & $908[0.95]$ & $267[0.79]$ & $808[0.93]$ \\
\hline & Folate polymorphic genotype [Frequency] & $48[0.05]$ & $71[0.21]$ & $62[0.07]$ \\
\hline
\end{tabular}

Table 2. Genotype frequency of folate regulator mutants MTR A2756G, MTRR A66G, MTHFR C677T and MTHFR A1298C among the DS bearing women stratified by meiotic errors. MI: Meiosis I; MII: Meiosis II; NDJ: Nondisjunction; N: number of individuals; $\chi^{2}$ :Chi square Fisher's exact test; OR: Odd Ratio; Cl: Confidence Interval; Two-tailed P value: $<0.05$ (P value after Bonferroni Correction test $<0.01667)$. 


\begin{tabular}{|c|c|c|c|c|c|c|}
\hline Variants & Genotype & $\begin{array}{l}\text { MI NDJ } \\
(\mathrm{N}=956)\end{array}$ & $\begin{array}{l}\text { MII NDJ } \\
(\mathrm{N}=338)\end{array}$ & $\chi^{2}$ & OR & $\begin{array}{l}95 \% \mathrm{Cl}, \\
\mathrm{P} \text { value }\end{array}$ \\
\hline \multirow[t]{3}{*}{ MTR A2756G } & AA & 0.9 & 0.57 & - & 1 & Reference \\
\hline & $A G$ & 0.08 & 0.41 & 195.84 & 8.15 & $5.92-11.23,<0.0001$ \\
\hline & GG & 0.02 & 0.02 & 0.737 & 1.64 & $0.68-3.96,0.391$ \\
\hline \multirow[t]{3}{*}{ MTRR A66G } & $\mathrm{AA}$ & 0.93 & 0.53 & - & 1 & Reference \\
\hline & $A G$ & 0.07 & 0.44 & 254.87 & 11.05 & $7.94-15.36,<0.0001$ \\
\hline & GG & - & 0.03 & 41.9 & 104.06 & $6.07-1785.2,<0.0001$ \\
\hline \multirow[t]{3}{*}{ MTHFR C677T } & $\mathrm{CC}$ & 0.95 & 0.82 & - & 1 & Reference \\
\hline & CT & 0.04 & 0.15 & 48.09 & 4.4 & $2.83-6.84,<0.0001$ \\
\hline & TT & 0.01 & 0.03 & 6.29 & 3.28 & $1.35-7.96,0.012$ \\
\hline \multirow[t]{3}{*}{ MTHFR A1298C } & $\mathrm{AA}$ & 0.94 & 0.35 & - & 1 & Reference \\
\hline & $A C$ & 0.06 & 0.55 & 448.31 & 24.86 & $17.46-35.40,<0.0001$ \\
\hline & $\mathrm{CC}$ & - & 0.1 & 200.73 & 523.76 & $31.88-8605.1,<0.0001$ \\
\hline
\end{tabular}

Table 3: Distribution of case-control women stratified by folate regulator genotype, SCT use status and maternal age at conception showing interactions among various risk factors and their association with case and control women. $\mathrm{N}$ : number of individuals; OR: Odd Ratio; Cl: Confidence Interval; P value: $<0.05$. 


\begin{tabular}{|c|c|c|c|c|c|c|c|c|}
\hline & Genotype & SCT use & Age & Number & \multicolumn{4}{|l|}{ Regression analysis } \\
\hline \multirow[t]{12}{*}{$\begin{array}{l}\text { Case } \\
(\mathrm{N}=1294)\end{array}$} & \multirow{6}{*}{$\begin{array}{l}\text { Folate } \\
\text { polymorphic } \\
\text { genotype } \\
(\mathrm{N}=376)\end{array}$} & \multirow{3}{*}{$\begin{array}{l}\text { Ever } \\
\text { user } \\
(\mathrm{N}=214)\end{array}$} & Young & 0.42 & $\begin{array}{l}\text { Interactions (maternal age } \times \text { SCT } \\
\text { use status } \times \text { polymorphism status) }\end{array}$ & OR & $\begin{array}{l}95 \% \\
\mathrm{Cl}\end{array}$ & $\begin{array}{l}\mathrm{P} \\
\text { value }\end{array}$ \\
\hline & & & Middle & 0.32 & \multirow{2}{*}{$\begin{array}{l}\text { Young } \times \text { SCT never user } \times \text { Wild } \\
\text { genotype }\end{array}$} & \multirow{2}{*}{\multicolumn{2}{|c|}{ Reference }} & \\
\hline & & & Old & 0.26 & & & & \\
\hline & & \multirow{3}{*}{$\begin{array}{l}\text { Never } \\
\text { user } \\
(\mathrm{N}=162)\end{array}$} & Young & 0.42 & \multirow{2}{*}{$\begin{array}{l}\text { Young } \times \text { SCT never-user } \times \text { Folate } \\
\text { polymorphic genotype }\end{array}$} & \multirow[t]{2}{*}{1.56} & \multirow{2}{*}{$\begin{array}{l}0.98 \\
- \\
2.49\end{array}$} & \multirow[t]{2}{*}{0.063} \\
\hline & & & Middle & 0.31 & & & & \\
\hline & & & Old & 0.27 & \multirow{2}{*}{$\begin{array}{l}\text { Young } \times \text { SCT ever-user } \times \text { Wild } \\
\text { genotype }\end{array}$} & \multirow[t]{2}{*}{1.22} & 0.86 & \multirow[t]{2}{*}{0.267} \\
\hline & \multirow{6}{*}{$\begin{array}{l}\text { Wild genotype } \\
(\mathrm{N}=918)\end{array}$} & \multirow{3}{*}{$\begin{array}{l}\text { Ever } \\
\text { user } \\
(\mathrm{N}=250)\end{array}$} & Young & 0.46 & & & 1.74 & \\
\hline & & & Middle & 0.33 & $\begin{array}{l}\text { Young } \times \text { SCT ever user } \times \text { Folate } \\
\text { polymorphic genotype }\end{array}$ & 7.59 & $\begin{array}{l}3.61 \\
- \\
15.98\end{array}$ & 0 \\
\hline & & & Old & 0.21 & \multirow{2}{*}{$\begin{array}{l}\text { Middle } \times \text { SCT never-user } \times \text { Wild } \\
\text { genotype }\end{array}$} & \multirow[t]{2}{*}{0.4} & 0.31 & \multirow[t]{2}{*}{0} \\
\hline & & \multirow{3}{*}{$\begin{array}{l}\text { Never } \\
\text { user } \\
(\mathrm{N}=668)\end{array}$} & Young & 0.47 & & & 0.51 & \\
\hline & & & Middle & 0.35 & \multirow{2}{*}{$\begin{array}{l}\text { Middle } \times \text { SCT never-user } \times \text { Folate } \\
\text { polymorphic genotype }\end{array}$} & \multirow[t]{2}{*}{2.81} & 1.46 & \multirow[t]{2}{*}{0.002} \\
\hline & & & Old & 0.18 & & & 5.41 & \\
\hline \multirow{12}{*}{$\begin{array}{l}\text { Control } \\
(\mathrm{N}=870)\end{array}$} & \multirow{6}{*}{$\begin{array}{l}\text { Folate } \\
\text { polymorphic } \\
\text { genotype } \\
(\mathrm{N}=62)\end{array}$} & \multirow{3}{*}{$\begin{array}{l}\text { Ever } \\
\text { user } \\
(\mathrm{N}=16)\end{array}$} & Young & 0.5 & \multirow{2}{*}{$\begin{array}{l}\text { Middle } \times \text { SCT ever-user } \times \text { Wild } \\
\text { genotype }\end{array}$} & \multirow[t]{2}{*}{1.06} & 0.72 & \multirow[t]{2}{*}{0.777} \\
\hline & & & Middle & 0.31 & & & 1.55 & \\
\hline & & & Old & 0.19 & \multirow{2}{*}{$\begin{array}{l}\text { Middle } \times \text { SCT ever-user } \times \text { Folate } \\
\text { polymorphic genotype }\end{array}$} & \multirow[t]{2}{*}{9.32} & 3.70 & \multirow[t]{2}{*}{0} \\
\hline & & Never & Young & 0.63 & & & 23.47 & \\
\hline & & & Middle & 0.26 & Old $\times$ SCT never-user $\times$ Wild & 1.16 & 0.82 & 0.403 \\
\hline & & & Old & 0.11 & & & 1.63 & \\
\hline & Wild genotype & Ever & Young & 0.48 & Old $\times$ SCT never-user $\times$ Folate & 5.94 & 2.32 & 0 \\
\hline & & $(N=130)$ & Middle & 0.41 & & & 15.22 & \\
\hline & & & Old & 0.11 & Old $\times$ SCT ever-user $\times$ Wild genotype & 2.51 & 1.36 & 0.003 \\
\hline & & Never & Young & 0.32 & & & 4.64 & \\
\hline & & $(\mathrm{N}=678)$ & Middle & 0.58 & Old $\times$ SCT ever-user $\times$ Folate & 12.38 & 3.82 & 0 \\
\hline & & & Old & 0.1 & & & 40.07 & \\
\hline
\end{tabular}

Table 4: Distribution of case women stratified by meiotic errors, folate regulator genotype and SCT use status and maternal age at conception showing interactions among various risk factors and their association with MI and MII error groups. MI: Meiosis I; MII: Meiosis II; N: number of individuals; OR: Odd Ratio; Cl: Confidence Interval; P value: $<0.05$. 


\begin{tabular}{|c|c|c|c|c|c|c|c|c|}
\hline & Genotype & SCT use & Age & Number & \multicolumn{4}{|l|}{ Regression analysis } \\
\hline \multirow[t]{12}{*}{$\begin{array}{l}\mathrm{Ml} \\
(\mathrm{N}=956)\end{array}$} & \multirow{6}{*}{$\begin{array}{l}\text { Folate } \\
\text { polymorphic } \\
\text { genotype } \\
(\mathrm{N}=138)\end{array}$} & \multirow{3}{*}{$\begin{array}{l}\text { Ever } \\
\text { user } \\
(\mathrm{N}=70)\end{array}$} & Young & 0.43 & $\begin{array}{l}\text { Interactions (maternal age } \times \text { SCT use } \\
\text { status } \times \text { polymorphism status) }\end{array}$ & OR & $\begin{array}{l}95 \% \\
\mathrm{Cl}\end{array}$ & $\begin{array}{l}\mathrm{P} \\
\text { value }\end{array}$ \\
\hline & & & Middle & 0.33 & \multirow{2}{*}{$\begin{array}{l}\text { Young } \times \text { SCT never user } \times \text { Wild } \\
\text { genotype }\end{array}$} & \multirow{2}{*}{\multicolumn{2}{|c|}{ Reference }} & \\
\hline & & & Old & 0.24 & & & & \\
\hline & & \multirow{3}{*}{$\begin{array}{l}\text { Never } \\
\text { user } \\
(\mathrm{N}=68)\end{array}$} & Young & 0.41 & \multirow{2}{*}{$\begin{array}{l}\text { Young } \times \text { SCT never-user } \times \text { Folate } \\
\text { polymorphic genotype }\end{array}$} & \multirow[t]{2}{*}{14.96} & \multirow{2}{*}{$\begin{array}{l}8.00 \\
-27.96\end{array}$} & \multirow[t]{2}{*}{0} \\
\hline & & & Middle & 0.31 & & & & \\
\hline & & & Old & 0.28 & \multirow{2}{*}{$\begin{array}{l}\text { Young } \times \text { SCT ever-user } \times \text { Wild } \\
\text { genotype }\end{array}$} & \multirow[t]{2}{*}{1.75} & 0.91 & \multirow[t]{2}{*}{0.095} \\
\hline & \multirow{6}{*}{$\begin{array}{l}\text { Wild genotype } \\
(\mathrm{N}=818)\end{array}$} & \multirow{3}{*}{$\begin{array}{l}\text { Ever } \\
\text { user } \\
(\mathrm{N}=213)\end{array}$} & Young & 0.46 & & & 3.39 & \\
\hline & & & Middle & 0.33 & $\begin{array}{l}\text { Young } \times \text { SCT ever user } \times \text { Folate } \\
\text { polymorphic genotype }\end{array}$ & 21.48 & $\begin{array}{l}11.91 \\
38.74\end{array}$ & 0 \\
\hline & & & Old & 0.21 & \multirow{2}{*}{$\begin{array}{l}\text { Middle } \times \text { SCT never-user } \times \text { Wild } \\
\text { genotype }\end{array}$} & \multirow[t]{2}{*}{1.06} & 0.59 & \multirow[t]{2}{*}{0.084} \\
\hline & & \multirow{3}{*}{$\begin{array}{l}\text { Never } \\
\text { user } \\
(\mathrm{N}=605)\end{array}$} & Young & 0.48 & & & 1.93 & \\
\hline & & & Middle & 0.35 & \multirow{2}{*}{$\begin{array}{l}\text { Middle } \times \text { SCT never-user } \times \text { Folate } \\
\text { polymorphic genotype }\end{array}$} & \multirow[t]{2}{*}{14.83} & 7.47 & \multirow[t]{2}{*}{0} \\
\hline & & & Old & 0.17 & & & 29.46 & \\
\hline \multirow{12}{*}{$\begin{array}{l}\mathrm{MII} \\
(\mathrm{N}=338)\end{array}$} & \multirow{6}{*}{$\begin{array}{l}\text { Folate } \\
\text { polymorphic } \\
\text { genotype } \\
(\mathrm{N}=237)\end{array}$} & \multirow{3}{*}{$\begin{array}{l}\text { Ever } \\
\text { user } \\
(\mathrm{N}=144)\end{array}$} & Young & 0.42 & \multirow{2}{*}{$\begin{array}{l}\text { Middle } \times \text { SCT ever-user } \times \text { Wild } \\
\text { genotype }\end{array}$} & \multirow[t]{2}{*}{1.82} & 0.88 & \multirow[t]{2}{*}{0.108} \\
\hline & & & Middle & 0.32 & & & 3.76 & \\
\hline & & & Old & 0.26 & \multirow{2}{*}{$\begin{array}{l}\text { Middle } \times \text { SCT ever-user } \times \text { Folate } \\
\text { polymorphic genotype }\end{array}$} & \multirow[t]{2}{*}{21.48} & 11.36 & \multirow[t]{2}{*}{0} \\
\hline & & Never & Young & 0.42 & & & 40.63 & \\
\hline & & $(\mathrm{N}=93)$ & Middle & 0.31 & Old $\times$ SCT never-user $\times$ Wild genotype & 1.77 & 0.93 & 0.083 \\
\hline & & & Old & 0.27 & & & 3.39 & \\
\hline & Wild genotype & Ever & Young & 0.45 & Old $\times$ SCT never-user $\times$ Folate & 14.13 & 6.91 & 0 \\
\hline & & $(\mathrm{N}=36)$ & Middle & 0.33 & & & 28.89 & \\
\hline & & & Old & 0.22 & Old $\times$ SCT ever-user $\times$ Wild genotype & 1.95 & 0.83 & 0.123 \\
\hline & & Never & Young & 0.42 & & & 4.57 & \\
\hline & & $(\mathrm{N}=65)$ & Middle & 0.32 & Old $\times$ SCT ever-user $\times$ Folate & 24.01 & 11.99 & 0 \\
\hline & & & Old & 0.26 & & & 48.09 & \\
\hline
\end{tabular}

Table 5.Distribution of amount of recombination events among case women stratified by folate regulator genotype, SCT use status and age at conception. MII: Meiosis II; N: number of individuals; WNU: Wild type Never User; WEU: Wild type Ever User; FNU: Folate variant Never user; FEU: Folate variant Ever User; df: Degrees of freedom; $P$ value: $<0.05$. 


\begin{tabular}{|c|c|c|c|c|c|c|c|}
\hline \multirow[t]{2}{*}{ Category } & \multirow[t]{2}{*}{$\begin{array}{l}\text { SCT-use } \\
\text { Status }\end{array}$} & \multirow[t]{2}{*}{ Age group } & \multirow[t]{2}{*}{$\mathbf{N}$} & \multicolumn{3}{|c|}{$\begin{array}{l}\text { Number of observed } \\
\text { recombination }\end{array}$} & \multirow{3}{*}{$\begin{array}{l}\text { Chi square value and } \\
P \text { value } \\
d f=2\end{array}$} \\
\hline & & & & & 1 & $\geq 2$ & \\
\hline & & & & 0 & & & \\
\hline \multirow[t]{10}{*}{ MII mothers with wild genotype } & \multirow{4}{*}{$\begin{array}{l}\text { Never user } \\
(\mathrm{N}=64)\end{array}$} & $\begin{array}{l}\text { Young }(\leq 28 \\
\text { yrs.) }\end{array}$ & 27 & N.A. & 0.52 & 0.48 & \multirow{6}{*}{$\begin{array}{l}\text { Young } \\
\text { WNU vs WEU: } 5.621, \\
0.018 \\
\text { WNU vs FNU: } 5.617, \\
0.018 \\
\text { WNU vs FEU: } 11.689 \text {, } \\
0.0006 \\
\text { WEU vs FNU: } 0.490 \text {, } \\
0.484 \\
\text { WEU vs FEU: } 0.018 \text {, } \\
0.893 \\
\text { FNU vs FEU: } 0.765 \text {, } \\
0.382\end{array}$} \\
\hline & & $\begin{array}{l}\text { Middle (29-34 } \\
\text { yrs.) }\end{array}$ & 20 & N.A. & 0.44 & 0.56 & \\
\hline & & & & & & & \\
\hline & & Old ( $\geq 35$ yrs.) & 17 & N.A. & 0.32 & 0.68 & \\
\hline & \multirow{6}{*}{$\begin{array}{l}\text { Ever user } \\
(\mathrm{N}=36)\end{array}$} & Young ( $\leq 28$ & 16 & N.A. & 0.85 & 0.15 & \\
\hline & & yrs.) & & & & & \\
\hline & & $\begin{array}{l}\text { Middle (29-34 } \\
\text { yrs.) }\end{array}$ & 12 & N.A. & 0.60 & 0.40 & \\
\hline & & & & & & & $\begin{array}{l}\text { WNU vs WEU: } 0.533 \text {, } \\
0.466\end{array}$ \\
\hline & & Old ( $\geq 35$ yrs.) & 8 & N.A. & 0.51 & 0.49 & $\begin{array}{l}\text { WNU vs FNU: 1.637, } \\
0.201\end{array}$ \\
\hline & & & & & & & $\begin{array}{l}\text { WNU vs FEU: } 2.768 \\
0.096\end{array}$ \\
\hline \multirow{10}{*}{$\begin{array}{l}\text { Mll mothers with folate polymorphic } \\
\text { genotype }\end{array}$} & \multirow{5}{*}{$\begin{array}{l}\text { Never user } \\
(\mathrm{N}=94)\end{array}$} & $\begin{array}{l}\text { Young ( } \leq 28 \\
\text { yrs.) }\end{array}$ & 39 & N.A. & 0.80 & 0.20 & \multirow{3}{*}{$\begin{array}{l}\text { WEU vs FNU: } 0.091 \text {, } \\
0.763 \\
\text { WEU vs FEU: } 0.293 \text {, } \\
0.588 \\
\\
\text { FNU v FEU: } 0.091 \\
0.763\end{array}$} \\
\hline & & & & & & & \\
\hline & & $\begin{array}{l}\text { Middle (29-34 } \\
\text { yrs.) }\end{array}$ & 30 & N.A. & 0.62 & 0.38 & \\
\hline & & Old ( $\geq 35$ yrs.) & 25 & N.A. & 0.52 & 0.48 & Old \\
\hline & & & & & & & $\begin{array}{l}\text { WNU vs WEU: } 1.001 \\
0.317\end{array}$ \\
\hline & \multirow{5}{*}{$\begin{array}{l}\text { Ever user } \\
(\mathrm{N}=144)\end{array}$} & $\begin{array}{l}\text { Young ( } \leq 28 \\
\text { yrs.) }\end{array}$ & 58 & N.A. & 0.87 & 0.13 & $\begin{array}{l}\text { WNU vs FNU: } 2.108 \\
0.147\end{array}$ \\
\hline & & & & & & & \multirow{2}{*}{$\begin{array}{l}\text { WNU vs FEU: } 2.554 \\
0.110 \\
\text { WEU vs FNU: } 0.010 \\
0.922\end{array}$} \\
\hline & & $\begin{array}{l}\text { Middle (29-34 } \\
\text { yrs.) }\end{array}$ & 48 & N.A. & 0.66 & 0.36 & \\
\hline & & & & & & & $\begin{array}{l}\text { WEU vs FEU: } 0.183 \text {, } \\
0.892\end{array}$ \\
\hline & & Old ( $\geq 35$ yrs.) & 38 & N.A. & 0.53 & 0.44 & $\begin{array}{l}\text { FNU vs FEU: } 0.002 \text {, } \\
0.961\end{array}$ \\
\hline
\end{tabular}


Table 6.Spatial distribution of single recombinant events on 21q among the case women stratified by genotype, SCT use status and maternal age at conception. MII: Meiosis Il; N: number of individuals; WNU: Wild type Never User; WEU: Wild type Ever User; FNU: Folate variant Never user; FEU: Folate variant Ever User; df: Degrees of freedom; P value: $<0.05$. 


\begin{tabular}{|c|c|c|c|c|c|c|c|c|c|c|c|}
\hline \multirow{2}{*}{$\begin{array}{l}\text { Genotype } \\
\text { category }\end{array}$} & \multirow{2}{*}{$\begin{array}{l}\text { SCT-use } \\
\text { Status }\end{array}$} & \multirow{2}{*}{$\begin{array}{l}\text { Maternal } \\
\text { Age group } \\
\text { at } \\
\text { conception } \\
\text { of DS }\end{array}$} & \multirow[t]{2}{*}{$\mathbf{N}$} & \multicolumn{6}{|c|}{ Long arm of nondisjoined chromosome 21} & \multirow{2}{*}{$\begin{array}{l}\text { Average } \\
\text { interval }\end{array}$} & \multirow{2}{*}{$\begin{array}{l}\text { Chi } \\
\text { square } \\
\text { value } \\
\text { and } P \\
\text { value } \\
\text { df = } 5\end{array}$} \\
\hline & & & & $\begin{array}{l}\text { Interval } \\
1\end{array}$ & $\begin{array}{l}\text { Interval } \\
2\end{array}$ & $\begin{array}{l}\text { Interval } \\
\mathbf{3}\end{array}$ & $\begin{array}{l}\text { Interval } \\
4\end{array}$ & $\begin{array}{l}\text { Interval } \\
5\end{array}$ & $\begin{array}{l}\text { Interval } \\
6\end{array}$ & & \\
\hline \multirow{13}{*}{$\begin{array}{l}\text { Mll mothers } \\
\text { with wild } \\
\text { genotype }\end{array}$} & & Young & 27 & 0.08 & 0.1 & 0.34 & 0.32 & 0.15 & 0.01 & 3.5 & Young \\
\hline & $\begin{array}{l}\text { Never } \\
\text { user } \\
(\mathrm{N}=64)\end{array}$ & & & & & & & & & & $\begin{array}{l}\text { WNU vs } \\
\text { WEU: } \\
2.716 \text {, } \\
0.744\end{array}$ \\
\hline & & Middle & 20 & 0.12 & 0.33 & 0.27 & 0.15 & 0.1 & 0.03 & 3.2 & $\begin{array}{l}\text { WNU vs } \\
\text { FNU: } \\
3.182 \\
0.672\end{array}$ \\
\hline & & & & & & & & & & & \multirow[t]{2}{*}{$\begin{array}{l}\text { WNU vs } \\
\text { FEU: } \\
81.312 \text {. } \\
<0.0001\end{array}$} \\
\hline & & Old & 17 & 0.35 & 0.29 & 0.18 & 0.11 & 0.06 & 0.01 & 2.5 & \\
\hline & & & & & & & & & & & $\begin{array}{l}\text { WEU vs } \\
\text { FNU: } \\
4.437 \\
0.488\end{array}$ \\
\hline & & Young & 16 & 0.03 & 0.11 & 0.35 & 0.33 & 0.16 & 0.02 & 3.52 & $\begin{array}{l}\text { FEU: } \\
94.159 \\
<0.0001\end{array}$ \\
\hline & $\begin{array}{l}\text { Ever } \\
\text { user } \\
(\mathrm{N}=36)\end{array}$ & & & & & & & & & & $\begin{array}{l}\text { FNU vs } \\
\text { FEU: } \\
74.385, \\
<0.0001\end{array}$ \\
\hline & & Middle & 12 & 0.1 & 0.35 & 0.24 & 0.17 & 0.09 & 0.05 & 3.21 & $\underline{\text { Middle }}$ \\
\hline & & & & & & & & & & & $\begin{array}{l}\text { WNU vs } \\
\text { WEU: } \\
1.095 \\
0.9546\end{array}$ \\
\hline & & & & & & & & & & & \multirow{2}{*}{$\begin{array}{l}\text { WNU vs } \\
\text { FNU: } \\
9.512 \\
0.090\end{array}$} \\
\hline & & Old & 8 & 0.4 & 0.3 & 0.15 & 0.1 & 0.03 & 0.02 & 2.49 & \\
\hline & & & & & & & & & & & $\begin{array}{l}\text { WNU vs } \\
\text { FEU: } \\
42.865 \text {, } \\
<0.0001\end{array}$ \\
\hline
\end{tabular}


WEU vs

FNU:

9.506,

0.090

MII mothers with folate polymorphic genotype
Never Young user

$(\mathrm{N}=94)$
$39 \quad 0.07$

0.15

0.38

0.3

0.09

0.02

3.5

WEU vs

FEU:

45.676, $<0.0001$

\begin{tabular}{|c|c|c|c|c|c|c|c|c|c|c|}
\hline & Middle & 30 & 0.11 & 0.19 & 0.35 & 0.25 & 0.05 & 0.05 & 3.21 & $\begin{array}{l}\text { FNU vs } \\
\text { FEU: } \\
58.696 \\
<0.0001\end{array}$ \\
\hline & Old & 25 & 0.42 & 0.31 & 0.17 & 0.06 & 0.02 & 0.01 & 2.5 & \multirow[t]{2}{*}{ Old } \\
\hline & Young & 58 & 0.49 & 0.32 & 0.12 & 0.04 & 0.03 & 0.01 & 3.49 & \\
\hline \multirow{2}{*}{$\begin{array}{l}\text { Ever } \\
\text { user } \\
(\mathrm{N}=144)\end{array}$} & Middle & 48 & 0.5 & 0.31 & 0.1 & 0.04 & 0.02 & 0.03 & 3.21 & \multirow{2}{*}{$\begin{array}{l}\text { WNU vs } \\
\text { WEU: } \\
9.888 \text {, } \\
0.079\end{array}$} \\
\hline & Old & 38 & 0.5 & 0.29 & 0.11 & 0.03 & 0.03 & 0.04 & 1.52 & \\
\hline
\end{tabular}

WNU vs FNU:

4.197,

0.521

WNU vs

FEU:

11.708 0.039

WEU vs

FNU:

3.965,

0.554

WEU vs FEU:

2.993,

0.701

FNUvs

FEU:

5.043, 0.411

\section{Figures}




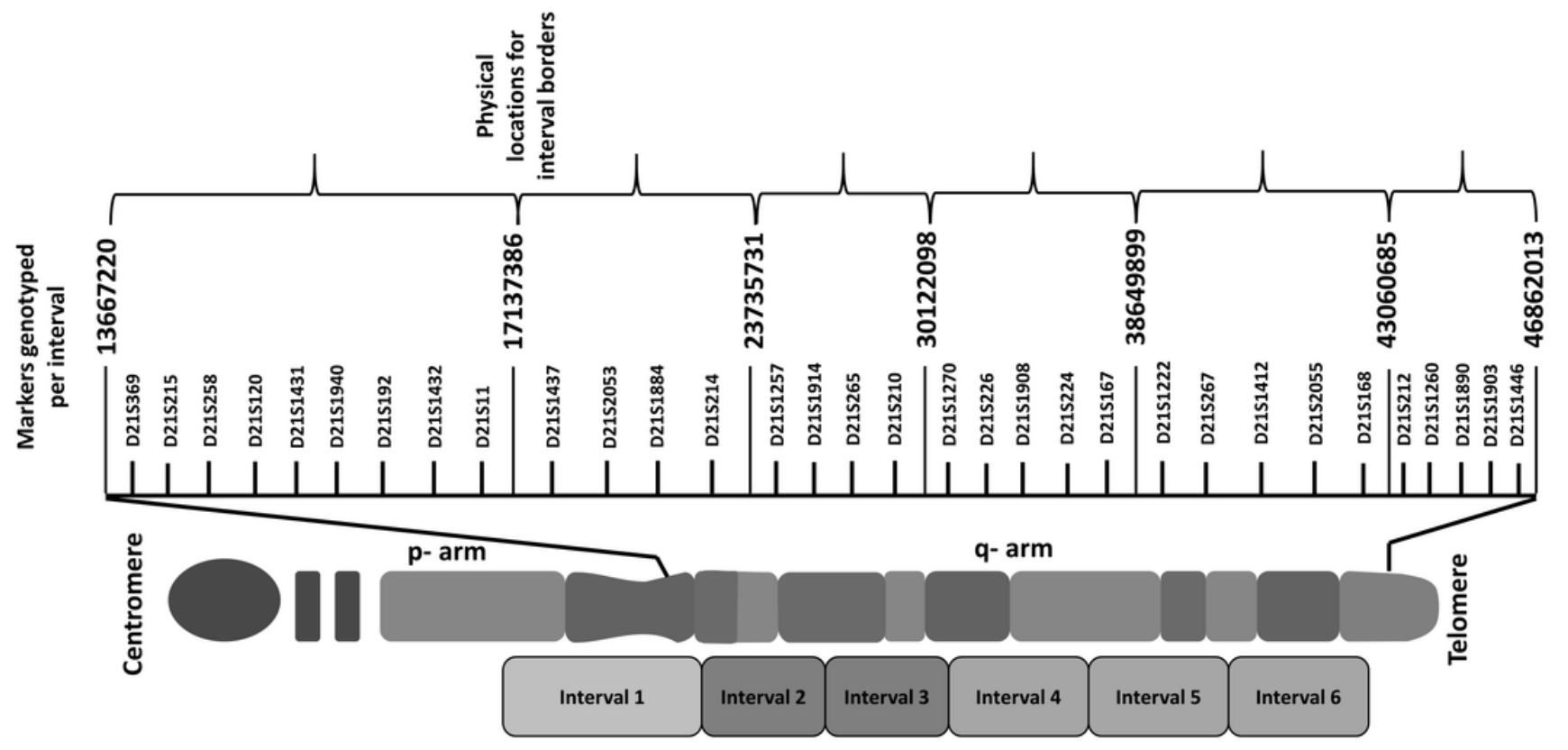

Figure 1

Universal STR markers used to define the origin of the meiotic error and determine the recombination profile. Panel of 32 universal STR markers were used to determine the parental origin (Maternal or Paternal) of error as well as type of meiotic error (Meiosis I or Meiosis II). Only cases in which the error was maternal in origin were included in this study. Once the origin of the error was defined, this genotyping information was used to determine the number and location of recombination (i.e., recombination profile). 21q was divided into six intervals of approximately equal physical length. Each observed recombinant was defined as being located in one of six defined intervals.

\section{Supplementary Files}

This is a list of supplementary files associated with this preprint. Click to download.

- Supplementarymaterials.pdf 